\title{
CADMIUM ZINC TELLURIDE SOLID-STATE DETECTOR CHARACTERISATION FOR ITS USE AS A SPECTRO-DOSEMETER
}

\author{
Nikola Kržanović' ${ }^{*}$, Annette Röttger ${ }^{2}$, Viacheslav Morosh², Maksym Luchkov², Stefan Neumaier ${ }^{2}$ \\ ${ }^{1}$ Vinča Institute of Nuclear Sciences, University of Belgrade (VINS), Belgrade, Serbia \\ ${ }^{2}$ Physikalisch-Technische Bundesanstalt (PTB), Braunschweig, Germany
}

\begin{abstract}
Concerning ionising radiation monitoring in the environment in areas which, by normal means, are inaccessible, e.g. in contaminated areas after a nuclear or radiological incident, the use of highly mobile systems, comprising of unmanned airborne vehicles equipped with ionising radiation detector, is advised in order to protect the health and the life of first responders. As a promising candidate, the compact solid-state spectrometer based on $C d Z n T e$ is characterised by performing irradiations in the reference radionuclide radiation fields of PTB. The energydependent conversion coefficients are derived from recorded pulse-height spectra, and they enable calculation of the operational radiation protection quantity, ambient dose equivalent rate, directly from the spectrum without deconvolution. The validity of the conversion coefficients was evaluated by determining the deviation of the calculated dose rate from the reference ambient dose equivalent rate for the ${ }^{226} \mathrm{Ra}$ radionuclide, available at the Underground Dosimetry Laboratory (UDO II) of PTB. By employing the derived conversion coefficients, the detector "linearity" (dose rate dependence of the response) was checked in the ${ }^{137}$ Cs reference fields of different ambient dose equivalent rates ranging from $25 \mathrm{nSv} / \mathrm{h}$ up to $1 \mu \mathrm{Sv} / \mathrm{h}$. The deviation of the calculated ${ }^{226} \mathrm{Ra}$ dose rate from the achieved reference value was $+2 \%$.
\end{abstract}

Keywords: Ambient dose equivalent rate, Detector characterisation, Environmental radiation monitoring, Lowdose rate dosimetry, Spectro-dosemeter

\section{INTRODUCTION}

Recent nuclear accident occurrences have accelerated the development of area dosemeter based environmental radiation monitoring networks of both, governmental and non-governmental origin which perform automatic acquisition of the dosimetric data and provide the community with prompt information on radioactive contamination of the environment [1]. The governmental networks consist of more than 5000 stations providing dose rate data on an hourly basis to the European Radiological Data Exchange Platform (EURDEP) [2], operated by the European Commission Joint Research Centre (EC JRC) in Ispra. The nongovernmental networks in most cases employ low-cost Geiger-Müller tube based measuring instruments, whose acquired data may not be accurate enough [3]. For the monitoring of contaminated areas which are not easily accessible by ground means, unmanned airborne radiation monitoring systems (UAMS) are being under development. These systems are comprised of unmanned airborne vehicles (UAV) on which compact ionising radiation detectors are installed. Prior to its integration into the UAMS, the radiation detector needs to be characterised. The ionising radiation detector used in this research is a compact $10 \times 10 \times 10 \mathrm{~mm}^{3}$ Cadmium Zinc Telluride
(CdZnTe, or CZT) solid-state detector manufactured by Kromek (detector model GR1-A+). This spectrometer exhibits high energy resolution ( $\leq 2 \%$ at ${ }^{137 C s}$ field) as stated by the manufacturer [4]. The detector itself does not require mandatory cooling due to its large energy band gap of the CdZnTe semiconductor material (approximately $1.57 \mathrm{eV}$, for $10 \%$ of $\mathrm{Zn}$ in the alloy) [5]. Firstly, the energy calibration of the spectrometer, i.e. assignment of the spectrometer channel number to the corresponding photon energy, is needed. The reference radionuclide data is available from the Decay Data Evaluation Project (DDEP) [6]. The ${ }^{241} \mathrm{Am},{ }^{137} \mathrm{Cs}$ and ${ }^{60} \mathrm{Co}$ radionuclide irradiation facilities available at Physikalisch-Technische Bundesanstalt (PTB), the national metrology institute of Germany, were used for this purpose. In order to perform accurate environmental monitoring of ionising radiation, the CdZnTe based solid-state detector was characterised for its use as a spectro-dosemeter which can be integrated into UAMS.

\section{PUlSE-HEIGHT SPECTRA TO AMBIENT DOSE EQUIVALENT RATE CONVERSION COEFFICIENT CALCULATION}

The CdZnTe spectro-dosemeter characterisation suggests derivation of the energy-dependent

\footnotetext{
*krzanovic@vin.bg.ac.rs
} 
conversion coefficients from the spectrometer recorded pulse-height spectra to the adequate operational radiation protection quantity, ambient dose equivalent rate, $H^{*}(10)$. To determine the conversion coefficients, a method which performs conversion of the complete spectra without deconvolution has been used [7]. According to this method, energy-dependent conversion coefficients are applied to the recorded pulse-height spectra. The ambient dose equivalent rate can be estimated as the inner product of the conversion coefficient vector and the vector containing the recorded pulse-height spectra values:

$$
H^{*}(10)=\vec{W}(E) * \vec{N}(E)
$$

The conversion coefficients are determined by irradiating the spectro-dosemeter in the reference radionuclide radiation fields which have sufficient gamma photon emission probabilities so that they cause prominent photoelectric absorption peaks in the recorded pulse-height spectra. In order to calculate the ambient dose equivalent rate, the total recorded pulseheight spectrum is divided into energy regions, where each of the regions contains one prominent photoelectric absorption peak:

$$
H^{*}(10)=\sum_{i} w_{i} E_{i} \cdot n_{i}
$$

where $w_{i}$ are the energy-dependent pulse-height spectra to ambient dose equivalent rate conversion coefficients, $E_{i}$ are the photon energies, and $n_{i}$ are the number of counts (intensity) assigned to $i$ different energy regions (bins) of the spectra [8], [9]. For all the conversion coefficient estimation measurements, the detector was placed at a $2 \mathrm{~m}$ distance from the radiation source, at the gamma radionuclide reference irradiation facility available at the Underground Dosimetry Laboratory (UDO II) which is maintained by PTB. UDO II is installed in a pure rock salt mine $430 \mathrm{~m}$ below ground level, where the background radiation level is in the order of $1 \mathrm{nSv} / \mathrm{h}$ [1]. Owing to the fact that the large contributor to the total background radiation is the natural terrestrial radiation and that the terrestrial radiation spectra is mostly influenced by the presence of ${ }^{226} \mathrm{Ra}$ and its progenies as well as that the spectro-dosemeter would be used for environmental monitoring, the conversion coefficient estimated ambient dose equivalent rate was compared to the reference value of the ${ }^{226} \mathrm{Ra}$ ambient dose equivalent rate available at UDO II. The reference value of the ${ }^{226} \mathrm{Ra}$ ambient dose equivalent rate at UDO II was $282.6 \mathrm{nSv} / \mathrm{h}$.

\subsection{Three-bin conversion coefficient calculation}

In order to determine the ambient dose equivalent rate from the recorded pulse-height spectrum, the total spectrum can be divided into three energy regions. Therefore, the detector was irradiated at the UDO II reference fields of ${ }^{241} \mathrm{Am},{ }^{137} \mathrm{Cs}$ and ${ }^{60} \mathrm{Co}$, all of which exhibit prominent photopeaks in a wide energy range. The deviation of the calculated ${ }^{226} \mathrm{Ra}$ ambient dose equivalent rate from the reference value when three energy regions are employed is $+23 \%$.

\subsection{Four-bin conversion coefficient calculation}

The three-bin conversion coefficients' values greatly overestimate the Ra-226 dose rate compared to the reference value measured with a standard ionisation chamber. In order to have more reliable information regarding the interactions of the low-energy photons with the detector active volume, ${ }^{57} \mathrm{Co}$ radionuclide was introduced to the experiment. The total pulse-height spectrum has been divided into four energy regions. The overestimation of the ${ }^{226} \mathrm{Ra}$ dose rate for the fourbin conversion coefficients has been reduced down to $+13 \%$.

\subsection{Optimisation of the dose rate calculation by using ${ }^{226} \mathrm{Ra}$ dose rate as reference}

If the recorded pulse-height spectrum is divided into four energy regions, the ${ }^{226} \mathrm{Ra}$ calculated ambient dose equivalent rate deviation from the reference value can be minimised by varying the bin sizes. The achieved deviation from the reference UDO II value after performing the minimisation is $+2 \%$. In Fig. 1 and Table 1, the conversion coefficient values are displayed for the three-bin, four-bin, and ${ }^{226} \mathrm{Ra}$ optimisation.

Table 1. Derived conversion coefficient values from the recorded pulse-height spectra to the ambient dose equivalent

\begin{tabular}{|c|c|c|c|c|}
\hline \multirow[b]{2}{*}{$\begin{array}{c}\text { Radiation } \\
\text { source }\end{array}$} & \multirow[b]{2}{*}{$E[\mathrm{keV}]$} & \multicolumn{3}{|c|}{ w [fSv/keV] } \\
\hline & & $\begin{array}{l}\text { Three } \\
\text { bins }\end{array}$ & $\begin{array}{l}\text { Four } \\
\text { bins }\end{array}$ & $\begin{array}{c}\mathrm{Ra}-226 \\
\min \end{array}$ \\
\hline${ }^{241} \mathrm{Am}$ & 59.54 & 9.4 & 9.4 & 9.44 \\
\hline $57 \mathrm{Co}$ & 122.06 & / & 5.6 & 5.51 \\
\hline $137 \mathrm{Cs}$ & 661.65 & 30.5 & 32.2 & 34.35 \\
\hline${ }^{60} \mathrm{Co}$ & $\begin{array}{l}1173.23 \\
1332.49\end{array}$ & 48.3 & 40.9 & 38.88 \\
\hline
\end{tabular}
rate

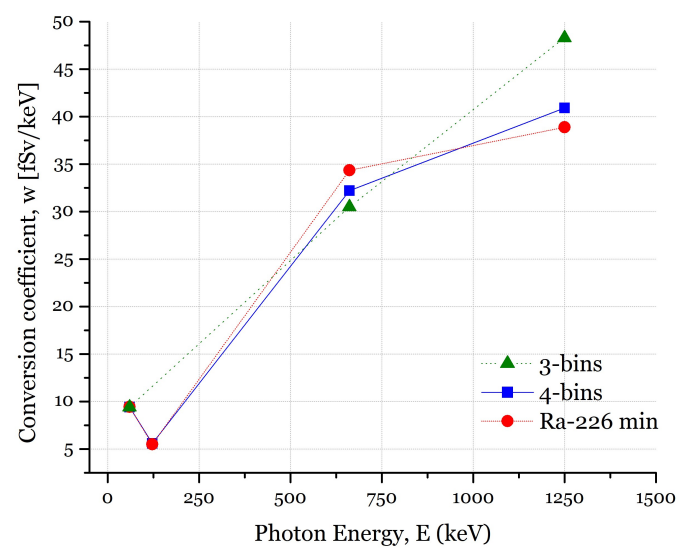

Figure 1. The energy-dependent conversion coefficients from pulse-height spectra to the ambient dose equivalent rate

\subsection{Conversion function}

The further step in the ambient dose equivalent rate calculation is the derivation of the continuous energy-dependent conversion function from the recorded pulse-height spectra to the ambient dose 
equivalent rate, instead of the discrete conversion coefficient values assigned to each of the energy regions. The conversion function $h(E)$ was derived by fitting the model function to the previously acquired experimental conversion coefficient data. According to the four-bin calculation, the conversion function should firstly be monotonously decreasing due to the high probability of photon detection in the active volume and the high interaction probability with the detector housing up to the energy of 57Co. Secondly, it should be monotonously increasing to the energy of ${ }^{137} \mathrm{Cs}$ with a saturation for the photon energies higher than ${ }^{60} \mathrm{Co}$ due to the detection efficiency falloff for high-energy photons [8]. Therefore, the proposed model function consists of two exponential saturation functions [10]:

$$
\begin{aligned}
& f(E)=a \cdot e^{-b \cdot E} \\
& g(E)=c \cdot\left(1-e^{-d \cdot E^{2}}\right) \\
& h(E)=f(E)+g(E)
\end{aligned}
$$

where $a, b, c, d$ are the fit parameters, and $E$ is the recorded photon energy. The discrete values of conversion coefficients optimised for ${ }^{226} \mathrm{Ra}$ dose rate calculation were used for the experimental data analysis. In order to increase the stability of the conversion function $(h(E))$ fitting procedure, an additional value of the conversion coefficient was fabricated and added to the experimental data, since the fit function has four parameters. The deviation of the calculated ${ }^{226} \mathrm{Ra}$ ambient dose equivalent rate determined with the conversion function from the reference value was $-14 \%$. Opposing to the discrete conversion coefficient binning methods, the ambient dose equivalent rate is underestimated when using the conversion function for the calculation. The conversion function and the discrete conversion coefficient values are displayed in Fig. 2.

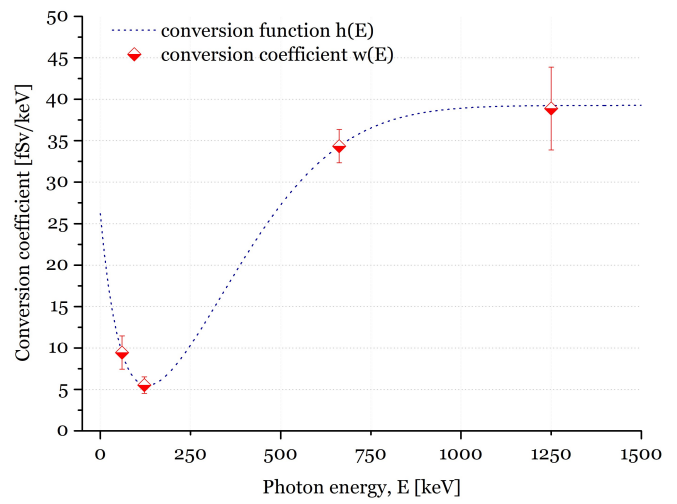

Figure 2. Energy-dependent conversion function from the pulse-height spectra to the ambient dose equivalent rate with the conversion coefficient values optimised for ${ }^{226} \mathrm{Ra}$ dose rate calculation

\section{DOSE RATE DEPENDENCE OF THE SPECTRO- DOSEMETER RESPONSE}

Linearity of the CdZnTe detector was tested in the reference fields produced by ${ }^{137} \mathrm{Cs}$ radionuclide sources of different dose rates. Irradiation values in the ambient dose equivalent rate range from $25 \mathrm{nSv} / \mathrm{h}$ up to $178.6 \mathrm{nSv} / \mathrm{h}$ were performed at the UDO II laboratory, and the higher dose rate values were

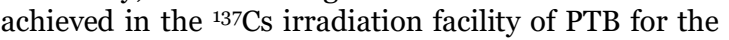
dose rate range from $300 \mathrm{nSv} / \mathrm{h}$ to $1 \mu \mathrm{Sv} / \mathrm{h}$. Linearity of the ${ }^{137} \mathrm{Cs}$ dose rates was tested for all of the pulseheight spectrum to ambient dose equivalent rate conversion methods presented in Section 2. Respective background radiation levels at UDO II and the PTB ${ }^{137} \mathrm{Cs}$ irradiation facility were subtracted from the measured values. Linearity results are presented as the deviations from the reference ${ }^{137} \mathrm{Cs}$ dose rate values in Table 2.

Table 2. Dose rate dependence of the spectro-dosemeter

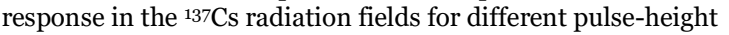
spectrum to ambient dose equivalent rate conversion methods

\begin{tabular}{|c|c|c|c|c|}
\hline \multirow{2}{*}{$\begin{array}{c}\text { Reference value } \\
{[\mathrm{nSv} / \mathrm{h}]}\end{array}$} & \multicolumn{4}{|c|}{$\begin{array}{c}\text { Deviation from the ref. value } \\
{[\%]}\end{array}$} \\
\cline { 2 - 5 } & $\begin{array}{c}\text { w(E) } \\
3 \text {-bin }\end{array}$ & $\begin{array}{c}\text { w(E) } \\
\text { 4-bin }\end{array}$ & $\begin{array}{c}\text { w(E) } \\
\text { Ra-min }\end{array}$ & $h(E)$ \\
\hline 25 & 15.8 & 14.5 & 14.1 & -4.6 \\
\hline 48.3 & 7.4 & 6.3 & 6.5 & -10.5 \\
\hline 102.2 & 1.4 & 1.1 & 3.4 & -13.1 \\
\hline 178.6 & 0.4 & 0.3 & 0.5 & -16.1 \\
\hline 297.0 & 24.9 & 22.9 & 22.2 & 0.5 \\
\hline 594.5 & 13.6 & 12.7 & 12.8 & -7.0 \\
\hline 991.0 & 14.8 & 12.2 & 12.1 & -7.8 \\
\hline & & & & \\
\hline
\end{tabular}

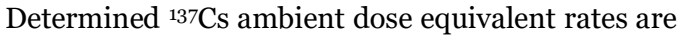
overestimated for all the calculations where conversion coefficients are being utilized. In case of the conversion function, similarly to the ${ }^{226} \mathrm{Ra}$ dose rate estimation,

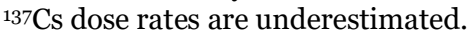

\section{CONCLUSION}

The CdZnTe based solid-state detector was characterised to be used for the precise airborne environmental monitoring of ionising radiation. The conversion coefficients and the conversion function from recorded pulse-height spectra to the operational dosimetric quantity used for environmental monitoring, ambient dose equivalent rate, were estimated by using radionuclide sources available at UDO II laboratory of PTB. The accuracy of this estimation was tested against the reference ${ }^{226} \mathrm{Ra}$ dose rate value measured with a Reuter-Stokes highpressure ionisation chamber. The calculated dose rate values for the ${ }^{226} \mathrm{Ra}$ dose rate and the ${ }^{137 \mathrm{Cs}}$ linearity test were an overestimation for all the derived conversion coefficient values, while the calculated dose rate for the conversion function was an underestimation compared to the mentioned reference dose rate values. With the ${ }^{226} \mathrm{Ra}$ deviation optimisation for the four energy region calculation, the deviation of $+2 \%$ is achieved which is 
satisfactory for the environmental monitoring purpose. The underresponse of $-14 \%$ achieved with the conversion function could be improved by adding more radionuclide sources in the energy ranges between ${ }^{57 \mathrm{Co}}$ and ${ }^{137} \mathrm{Cs}$ and the high photon energies above ${ }^{60} \mathrm{Co}$ by either performing further experiments or Monte Carlo simulations of the detection process in the CdZnTe solid-state detector.

Acknowledgements: The research presented in this paper was realised within 16ENVo4 Preparedness project via the Research Mobility Grant (RMG). The $R M G$ researcher has received funding from the EMPIR programme co-financed by the Participating States and from the European Union's Horizon 2020 research and innovation programme. The authors would like to thank Christian Fuhg, Phil Brüggemann, Jörg Kretzer and Karsten Kahnt for the support of the measurements.

\section{REFERENCES}

1. S. Neumaier, H. Dombrowski, "EURADOS intercomparisons and the harmonisation of environmental radiation monitoring," Radiat. Prot. Dosim, vol. 160, no. 4, pp. 297 - 305, Aug. 2014. DOI: $10.1093 / \mathrm{rpd} /$ ncuoo2 PMid: 24497552

2. Radiological maps, Real-time monitoring, European Commission Joint Research Centre (EC JRC), Brussels, Belgium.

Retrieved from: https://remap.jrc.ec.europa.eu/ Retrieved on: Jul. 12, 2019.

3. N. Kržanović, K. Stanković, M. Živanović, M. Đaletić, O. Ciraj-Bjelac, "Development and testing of a low cost radiation protection instrument based on an energy compensated Geiger-Müller tube," Radiat. Phys. Chem., vol. 164, Nov. 2019.

DOI: 10.1016/j.radphyschem.2019.108358
4. GR1 CZT gamma-ray detector spectrometer, Kromek Group plc, Zelienople (PA), USA.

Retrieved from:

https://www.kromek.com/product/gamma-raydetector-spectrometers-czt-based-gr-range/ Retrieved on: Jul. 10, 2019.

5. C. Szeles, "CdZnTe and CdTe materials for X-ray and gamma ray radiation detector applications," Phys. Status Solidi, vol. 241, no. 3, pp. 783 - 790, Mar. 2004. DOI: $10.1002 / p s s b .200304296$

6. M. M. Be et al., Table of Radionuclides (Vol. $8-A=41$ 198), BIPM, Paris, France, 2016.

Retrieved from:

https://www.bipm.org/utils/common/pdf/monographi eRI/Monographie BIPM-5 Tables Vol8.pdf Retrieved on: Jun. 15, 2019

7. H. Dombrowski, "Area dose rate values derived from $\mathrm{NaI}$ or $\mathrm{LaBr}_{3}$ spectra," Radiat. Prot. Dosim., vol. 16o, no. 4, pp. 269 - 276, Aug. 2014.

DOI: $10.1093 / \mathrm{rpd} / \mathrm{nct} 349$ PMid: 24478307

8. P. Kessler, B. Behnke, H. Dombrowski, S. Neumaier, "Characterization of detector-systems based on $\mathrm{CeBr}_{3}$ $\mathrm{LaBr}_{3}, \mathrm{SrI}_{2}$ and CdZnTe for the use as dosemeters," Radiat. Phys. Chem., vol. 140, pp. $309-313$, Nov. 2017. DOI: 10.1016/j.radphyschem.2016.12.015

9. P. Kessler et al., "Novel spectrometers for environmental dose rate monitoring," J. Environ. Radioact., vol. 187, pp. 115 - 121, Jul. 2018.

DOI: 10.1016/j.jenvrad.2018.01.020 PMid: 29455914

10. A. Röttger, P. Kessler, "Uncertainties and characteristic limits of counting and spectrometric dosimetry systems," J. Environ. Radioact., vol. 205 - 206, pp. 48 - 54, Sep. 2019.

DOI: 10.1016/j.jenvrad.2019.04.012 PMid: 31102905 